\title{
Sequence-specific endonucleolytic cleavage and protection of mRNA in Xenopus and Drosophila
}

\author{
Bob D. Brown, ${ }^{1,3}$ Ilan D. Zipkin, ${ }^{2}$ and Richard M. Harland \\ Division of Biochemistry and Molecular Biology, University of California, Berkeley, California 94720 USA
}

Previously, a small region of the $3^{\prime}$-untranslated region ( $3^{\prime}$ UTR) of Xlhbox2B mRNA was shown to be sufficient for sequence-specific endonucleolytic cleavage after injection into Xenopus oocytes. Here, we report an in vitro RNA degradation reaction that mimics the in vivo result accurately. The reaction also reveals that oocytes contain a sequence-specific RNA-binding factor that inhibits the endoribonuclease. These opposing activities may be regulated during Xenopus oogenesis. Partial purification shows that the endonuclease does not require translation or ribosomes and does not resemble previously described RNA processing complexes. We have isolated another Xenopus cDNA, Xoo1, that contains a long, repetitive destabilizing element similar to the one in Xlhbox2B. Based on a comparison of these natural destabilizing sequences and in vitro mutagenesis experiments, we find that a single destabilizing site is, at most, 19 bases in length and that the endonuclease and protective factor recognition sites may be overlapping subsets of this sequence. Finally, we show that Drosophila embryos contain similar activities, each of which can use Xenopus recognition sites. This level of conservation suggests an important biological function for this system of post-transcriptional regulation.

[Key Words: mRNA; endoribonuclease; RNA stability; RNA degradation]

Received April 28, 1993; revised version accepted June 17, 1993.

The stability of mRNA plays a crucial role in the regulation of gene expression (for review, see Atwater et al. 1990|, and alterations in mRNA stability have been shown to cause cellular genes to become transforming (Lee et al. 1988; Aghib et al. 1990). In spite of this, RNA degradation has been poorly studied relative to the process of RNA synthesis. Although our knowledge of RNA degradation processes is limited, it is clear that specific regulation of RNA stability involves multiple factors and in many instances is complicated by requirements for polysomes or active translation (Stoeckle and Hanafusa 1989; Bandyopadhyay et al. 1990; Brewer 1991; Bernstein et al. 1992; Savant-Bhonsale and Cleveland 1992; You et al. 1992).

We have previously described the endonucleolytic degradation of synthetic Xlhbox2 [Müller et al. 1984; Wright et al. 1987); this gene is now known as $\operatorname{HoxB7}$ (Scott 1992)] mRNA in vivo by microinjecting synthetic RNAs into Xenopus oocytes (Brown and Harland 1990). Both 5' and $3^{\prime}$ cleavage products were detected using end-specific probes in S1, Northern, and oligodeoxynucleotide/ RNase $\mathrm{H}$ assays. A 90-base region of the Xlhbox2 3'-

Present addresses: ${ }^{1}$ Genta, Inc., Biology Division, San Diego, California 92121 USA; ${ }^{2}$ Department of Biochemistry and Biophysics, University of California, San Francisco, California 94143 USA.

${ }^{3}$ Corresponding author. untranslated region (3' UTR), notable for its repetitive sequence and lack of guanosine, was shown to be sufficient and necessary for cleavage. By using cycloheximide and 5' uncapped RNAs, the cleavage of RNAs containing these sequences was shown to be independent of translation.

Here, we examine the endonuclease activity and the recognition sequence in vitro using partially fractionated lysates made from Xenopus oocytes and embryos. The in vitro reaction accurately reproduces the in vivo cleavages (Brown and Harland 1990) and reveals a specific inhibitor that competes with the cleavage activity for recognition sites. In addition, comparisons of natural cleavage regions found in Xlhbox2 and Xoo1 (this work) combined with the in vitro reaction have been used to examine the sequences that are sufficient to form a single recognition site and to test artificial recognition sites. Finally, we have looked for the cleavage and recognition sites in other organisms to assess the conservation and, therefore, the likely importance of the cleavage and protective activities.

\section{Results}

In vitro cleavage reactions using Xenopus oocyte lysates mimic the in vivo reaction accurately

To characterize the sequence-specific endoribonuclease 
activity, we developed an in vitro reaction system using lysates made from Xenopus oocytes (see Materials and methods). The reaction accurately mimics the cleavage of Xlhbox2 RNA in vivo (Fig. 1). The ${ }^{32} \mathrm{P}$-labeled substrate Xhox 45 RNA (an independent isolate of Xlhbox2B described in Brown and Harland 1990) is shown in lane 1 (F). Incubations in a crude oocyte lysate (lane 2 ) produced new bands of the correct length to be the endonucleolytic degradation products $15^{\prime}$ and $3^{\prime}, 890$ and 570 bases long, respectively), as well as a smear of nonspecific degradation.

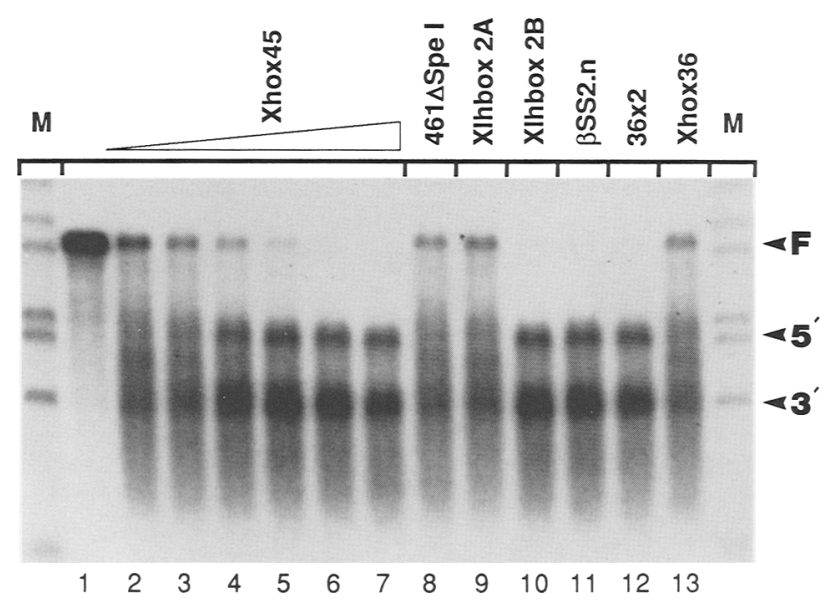

Figure 1. Sequence-specific in vitro cleavage of Xlhbox2B RNA and evidence for a sequence-specific protective factor in Xenopus oocytes. Eighty nanograms of ${ }^{32}$ P-labeled Xhox 45 RNA was incubated in an unoptimized in vitro cleavage reaction containing $210 \mu \mathrm{g}$ of protein $16.1 \mathrm{mg} / \mathrm{ml}$; see text and Materials and methods for Xenopus oocyte lysate) for $30 \mathrm{~min}$ at room temperature (lanes 2-13). The arrowheads mark (from top to bottom) full-length Xhox 45 ( 1460 bases long, described in Brown and Harland 1990), 5' cleavage products resulting from specific endonucleolytic cleavage of the Xhox45 RNA $(\sim 890$ bases in length), and $3^{\prime}$ cleavage products $(\sim 570$ bases long). Unlabeled RNAs were added as specific competitors to the reactions as shown (diagramed in Fig. 5 of Brown and Harland 1990). Lane 1 contains $80 \mathrm{ng}$ of unincubated, ${ }^{32} \mathrm{P}$-labeled Xhox 45 RNA. Lane 2 shows an identical sample of labeled $X$ hox 45 RNA that was incubated in lysate without any specific RNA competitor. Lanes 3-7 show a titration of the reaction with cold Xhox45 RNA from $0.1,0.25,0.5,1.0$, and $2.0 \mu \mathrm{g}$, respectively. Specific cleavage products can be detected within a smear of nonspecific degradation. Lanes 8-13 show specific enhancement of the cleavage reaction by competitor RNAs that contain the cleavage recognition sequence. Lanes 8 and 9 contained $2 \mu \mathrm{g}$ of cold $461 \Delta$ SpeI and Xlhbox $2 A$, respectively, and no enhancement of the reaction is seen. The only sequences in common among Xhox $45 / X 1 h b o x 2 B, \beta S S 2 . n$, and $36 \times 2$ are endonuclease recognition sites, and only these competitor RNAs enhance the cleavage reaction. $36 \times 2$ was described previously (Brown and Harland 1990). Xhox36 does not enhance cleavage of the labeled $X I h b o x 2 B$. Following the reactions, total RNA was reisolated and run in denaturing agarose as described previously. The size markers (M) are, from top to bottom, 1904, 1584, 1375, 947, 831, 564 , and 125 bases in length. Unlabeled torula (1.6 $\mu$ g) RNA was included in each reaction as a substrate for nonspecific RNase activities.
RNA species lacking the endonuclease target sequences are not cleaved in these lysates and have much longer half-lives. Xenopus neurotrophin-4 RNA (NT-4, Hallböök et al. 1991) was used as a control for base composition. The NT-4 3' UTR contains a region $>300$ bases in length, with only a small number of guanosines, and does not contain an Xlhbox2-like endoribonuclease recognition site as we confirmed by sequencing. NT-4 RNA proved to be stable in oocyte lysates (data not shown). Therefore, a base composition lacking guanosines is not sufficient for recognition by the endonuclease.

\section{The in vitro reaction reveals that Xenopus oocytes also contain an endoribonuclease inhibitor}

In addition to the endoribonuclease, oocytes contain a sequence-specific protective factor that can be titrated by unlabeled competitor RNA that contains the recognition sites (Fig. 1, lanes 2-7). Each reaction shown contained an identical amount of torula yeast RNA as a competitor for nonspecific RNase activities. Lane 2 shows $80 \mathrm{ng}$ of labeled Xhox45 RNA incubated in the crude lysate with no additional competitor. In lanes 3-7, increasing amounts of unlabeled Xhox45 RNA were added as a specific competitor for the endoribonuclease activity.

If the nuclease activity were saturable by specific competitor, the faint specific cleavage product bands within the smear of degradation products in lane 2 should disappear in lanes 3-7. In contrast, lanes 3-7 show that the specific cleavage fragment bands were enhanced and became the most abundant reaction products. This suggests that a saturable factor can bind to the recognition sequence and protect it from cleavage.

\section{The protective factor is also sequence specific}

Figure 1 also demonstrates that the endoribonuclease inhibitor itself is RNA sequence specific (lanes 7-13). Different species of cold competitor RNA were added to the in vitro reaction. Lane 7 shows complete cleavage of the labeled substrate when cold $X$ hox 45 RNA is added. An artificial deletion in the Xhox45 $3^{\prime}$ UTR that removes the instability sites ( $461 \Delta$ SpeI; see Fig. 5 of Brown and Harland 1990) eliminates the enhancement (lane 8). Xlhbox2A (Fritz et al. 1989) contains a natural deletion of the recognition sites and does not alter cleavage (lane 9|, whereas the otherwise identical Xlhbox2B RNA that contains the instability region enhances the reaction (lane 10). Insertion of the recognition sites into another competing RNA (36x2; Brown and Harland 1990) promotes cleavage (lane 12), whereas the parent Xhox36 with no recognition sequence does not (lane 13). A competitor globin RNA containing synthetic recognition sites ( $\beta S S 2 . n$, see Fig. 8, below) also enhances the cleavage reaction (lane 11), whereas the parent Xenopus $\beta$-globin RNA does not (data not shown).

From these results, it appears that competitor RNA molecules containing the endonuclease recognition sequences enhance the cleavage reaction, whereas related 
RNAs lacking the recognition sequences do not. A model of the system suggested by the data is given in Figure 2. Under limiting substrate conditions (Fig. 2A), ${ }^{32}$ P-labeled RNAs (1) containing endonuclease recognition sites (2) are bound and protected by the endonuclease inhibitor (3). Even under these conditions, the endoribonuclease (4) will be able to cleave some recognition sites if the off-rate of the protective factor is significant. When additional substrate RNA is added (Fig. 2B) the protective factor is titrated out among the additional recognition sites and thus the endonuclease can rapidly cleave the exposed sites, leading to the rapid degradation of all of the substrate RNA molecules.

The stimulation of cleavage by competitor is still evident in a reaction that is carried out under optimized conditions. Figure 3 shows a comparison of the reaction between RNAs derived from Xlhbox $2 B$ clones (named 461 and $461 \Delta$ SpeI, similar to $45 \Delta$ SpeI seen previously) in crude oocyte lysate. The reaction conditions used for

A
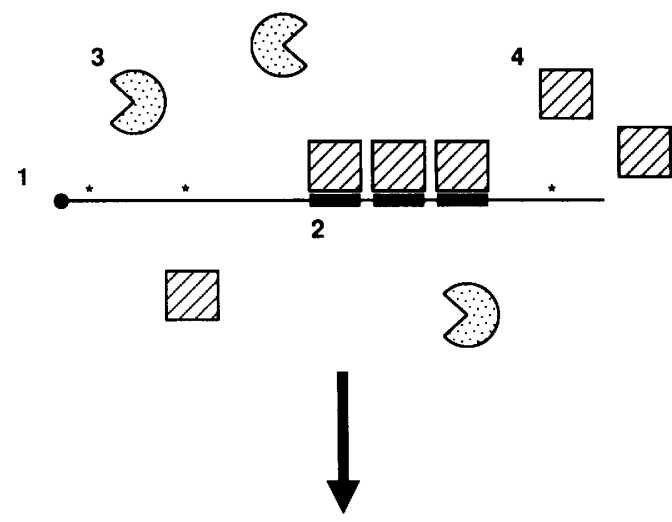

B

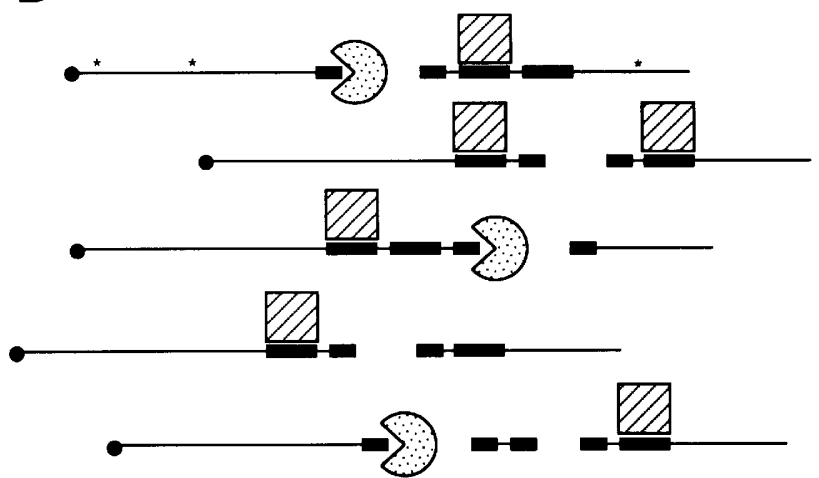

Figure 2. Xenopus oocytes contain a sequence-specific protective factor that binds the endoribonuclease recognition site. The results shown in Fig. 1 suggest the following model: In the initial conditions of the in vitro cleavage reaction $(A)$, the labeled substrate RNA (1), containing endonuclease recognition sites $(2)$ is bound and at least partially protected from the endoribonuclease (3) by a sequence-specific protective factor (4). The ${ }^{32} \mathrm{P}$ label is represented by an asterisk (*). When an excess of unlabeled substrate RNA is added to the reaction $(B)$ the protective factor is titrated out, leaving the endonuclease recognition sites exposed. Thus, the labeled and unlabeled RNA molecules are rapidly cleaved.

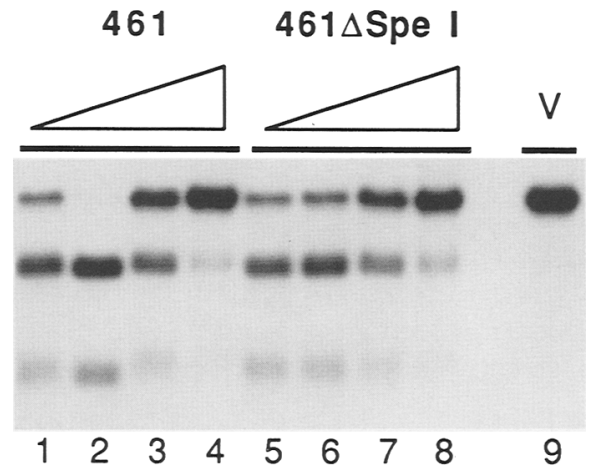

Figure 3. Saturation of the cleavage reaction by specific competitor RNA. Increasing amounts of competitor RNA in each reaction are represented by ramps above the lanes. All reactions contained a constant amount of a ${ }^{32} \mathrm{P}$-labeled substrate RNA and increasing amounts of unlabeled competitor RNA as follows: $0,1,4$, and $8 \mu \mathrm{g}$ of 461 RNA (cleavable Xlhbox2B RNA) was added to lanes $1-4$, respectively, $0,1,4$, and $8 \mu \mathrm{g}$ of $461 \Delta$ SpeI RNA (from which the instability sequence has been deleted) was added to lanes 5-8, respectively. Note that the addition of $1 \mu \mathrm{g}$ of cleavable RNA to the reaction drives the reaction to completion (lane 2) only if the competitor RNA contains the same recognition sites that are being cleaved in the labeled substrate RNA (lane 6). Both specific (lanes 3,4) and nonspecific (lanes 7,8 ) saturation of the cleavage reaction is seen at very high RNA concentrations. The ${ }^{32} \mathrm{P}$-labeled substrate RNA in these reactions (100 ng each) was made from an artificial construct designated $\beta S S 2.3$ (see Fig. 8). Lane 9 (V) shows $100 \mathrm{ng}$ of full-length, uncut $\beta S S 2.3$ prior to incubation in the in vitro cleavage reaction.

this assay were improved by using $\mathrm{KCl}$ instead of $\mathrm{NaCl}$ and raising the $\mathrm{pH}$ to 8.5 . As before, each reaction contained the same amount of cleavable substrate RNA /see legend), and increasing amounts of competitor RNA, from 0 to $8 \mu \mathrm{g}$, were added. Lanes 1 and 5 show the basal amount of cleavage under these conditions when no competitor is added. When $1.0 \mu \mathrm{g}$ of cold 461 (Xlhbox $2 B$ ) RNA is added to the reaction (lane 2), cleavage is complete. In comparison, lane 6 shows no enhancement of the reaction. As 4 and $8 \mu \mathrm{g}$ of $461 \mathrm{RNA}$ are added to the reaction (lanes 3,4 ), cleavage becomes saturated. If the substrate were self-cleaving, these saturation kinetics would not be expected.

\section{Regulation of the endonuclease and protective factor during early oogenesis}

To determine whether or not any component of this RNA stability regulatory system might be regulated during early development, lysates were made from staged oocytes and embryos. Figure 4 shows the results of competition assays using lysates made from early (stages I and II) and late (stages V and VI; Dumont 1972) oocytes. As before, increasing amounts of specific competitor RNA were added to the reaction series. As the competitor RNA is added to lysates made from early oocytes (lanes 3-7), only a small increase in the efficiency of 


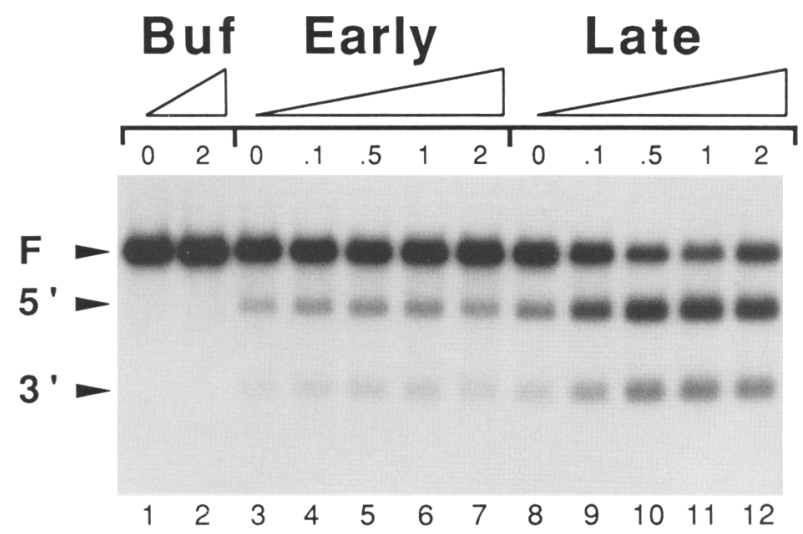

Figure 4. The endoribonuclease and protective factor activities may be regulated during oocyte development. Stage-specific lysates were made from stage I and II oocytes (Early, lanes 3-7) and stage $\mathrm{V}$ and VI oocytes (Late, lanes 8-12) and used in competition assays as described previously. One hundred nanograms of ${ }^{32}$ P-labeled $\beta S S 2.3$ (Fig. 8) was present in each reaction with increasing amounts of unlabeled 09.1B RNA (Fig. 6) as the competitor (given in $\mu \mathrm{g}$ above the lanes, represented by the ramps). Arrowheads at the left mark full length (F) BSS2.3 RNA and the $5^{\prime}$ and $3^{\prime}$ cleavage products. In lanes 3-7 only a slight increase can be seen in the efficiency of the cleavage reaction upon the addition of $0-2 \mu \mathrm{g}$ of competitor. In contrast, lanes 8-12 show a very strong increase in the efficiency of the endoribonuclease activity as competitor RNA is added /cf. lanes 8 and 11). Each reaction contained the same amount of protein. Arrowheads at the right represent markers at 947, 831, 564, and 125 bases in length. Oocyte stages are as defined by Dumont (1972). Control reactions with buffer (Buf) are shown in lanes 1 and 2.

cleavage is visible (cf. lanes 3 and 5). Under identical reaction conditions the lysate made from late-stage oocytes shows a different result: Enhancement of the cleavage reaction by competitor RNA is far more dramatic (cf. lanes 10,11, and 12 with lanes 6, 7, and 8). Because identical amounts of protein (crude lysate) were added to each reaction, the differential response to the addition of competitor RNA must be the result of an increase in the relative level of protective factor between early- and late-stage oocytes.

\section{Partial purification of the endonuclease}

Other RNA degradation systems have proved to be biochemically intractable, possibly owing the link between degradation and translation. In contrast, this endonuclease can be fractionated in good yield by column chromatography. Figure 5 shows the elution profile of the endoribonuclease activity from an FPLC Superose $12 \mathrm{col}-$ umn (Pharmacia). The peak of activity corresponds to a molecular mass of $\sim 123 \mathrm{kD}$. Therefore, the sequencespecific endonuclease does not require a large complex as in AUUUA degradation (>20S; Savant-Bhonsale and Cleveland 19921.

A possible mechanism of cleavage would be for a factor to bind to the mRNA and stimulate a separate cellu- lar RNase. RNasin had no effect on the specific endonuclease activity but does reduce the nonspecific degradation (data not shown). Thus, the endonuclease differs significantly from the pancreatic type of RNases commonly found in oocytes, which are inhibited by RNasin (Xing and Worcel 1989; Bandyopadhyay et al. 1990). The partial purification of the endonuclease also removes most contaminating ribonucleases. Thus, the data suggest that cleavage does not result from local exposure of the sequence to nonspecific nucleases by the removal of a binding factor but, rather, that the endonuclease activity resides directly in the $123-\mathrm{kD}$ factor itself.

Another gene in Xenopus, Xool, contains a destabilizing element related to Xlhbox $2 \mathrm{~B}$

We screened ovary lobtained from D. Melton, Harvard University, Cambridge, MA) and neurula cDNA libraries at low stringency with the XIhbox2B destabilizing sequence to identify additional genes in Xenopus containing similar elements. Two isolates from the neurula stage library were identified as Xlhbox $2 B$ clones by hybridization to a specific probe, but two isolates from the oocyte library proved to be different and were investigated further. Restriction mapping and sequencing revealed that the new oocyte cDNAs were independent clones of a single gene, which we have named Xoo1.

A partial restriction map of Xoo1 is shown in Figure $6 \mathrm{~A}$. The putative $3^{\prime}$ UTR contains $\sim 48$ repeats of a 20 -base element that closely resembles the 19-base $X 1 H b o x 2 B$ repeat. The first four repeats are identical to one another (Fig. 6B). An internal EcoRI site in the Xoo1 cDNA was used to produce the 09.1B subclone. Transcripts from this clone are cleaved rapidly when injected into Xenopus oocytes, and there is no evidence of a preference for any particular site within the region. 09.1B

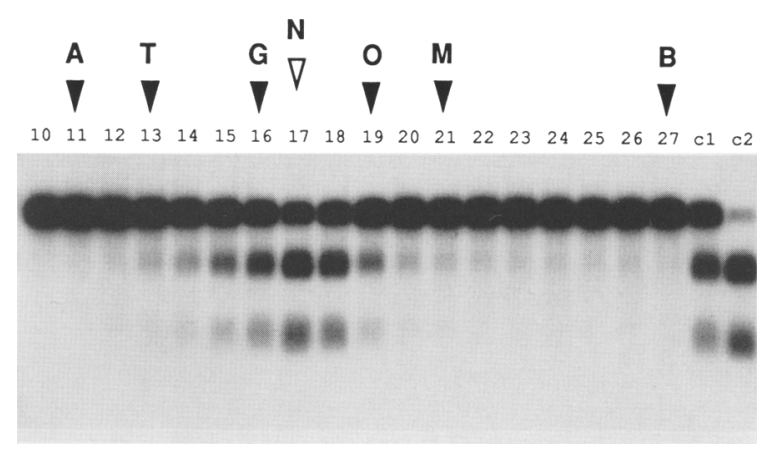

Figure 5. The endoribonuclease activity has an apparent molecular mass of $123 \mathrm{kD}$ by gel filtration. Assays of sizing column fractions are shown. Partially purified endoribonuclease activity was concentrated, mixed with gel filtration sizing standards (Bio-Rad), and run on a Superose-12 (Pharmacia) sizing column. The size standards (solid arrowheads) were aggregated material (A), $670 \mathrm{kD}(\mathrm{T}), 158 \mathrm{kD}(\mathrm{G}), 44 \mathrm{kD}(\mathrm{O}), 17 \mathrm{kD}(\mathrm{M})$, and $1.35 \mathrm{kD}$ (B). The peak of endoribonuclease ( $N$, open arrowhead) activity appeared in fraction 17 and had a molecular mass of $\sim 123 \mathrm{kD}$. $\mathrm{c} 1$ and $\mathrm{c} 2$ are positive controls. $\mathrm{M}$ (no arrowhead) and $\mathrm{U}$ are as given previously. 
Figure 6. Another Xenopus gene, Xoo1, has been found to contain Xlhbox2B-like instability sequences. $(A)$ A partial restriction map of Xoo1. The full cDNA sequence was assembled from four independent $\lambda$ gt 10 cDNAs. The hatched box represents the putative open reading frame; the open box comprising most of the $3^{\prime}$ UTR represents the instability sequence. The oligo(dT)-primed cDNAs were inserted into the vector phage using EcoRI linkers, but no evidence of an oligo(dT)primed poly(A) tail was found in any of the cDNAs. The internal EcoRI site at base 703 was used to subclone almost the entire $3^{\prime}$ UTR into a transcription vector to produce the $09.1 \mathrm{~B}$ clone. In vitro transcription of the 09.1B clone produces an RNA containing $\sim 40$ stability regulation sites in almost 900 bases of instability sequence. $5^{\prime}$ to $3^{\prime}$ is read left to right, and the scale shown below is accurate. $(B)$ Comparison of Xlhbox $2 B$ and Xoo1 instability sequences. The 120 -base instability region found in Xlhbox2B (top lines) is compared with the first 120 bases of the instability region found in the Xoo1 gene (bottom

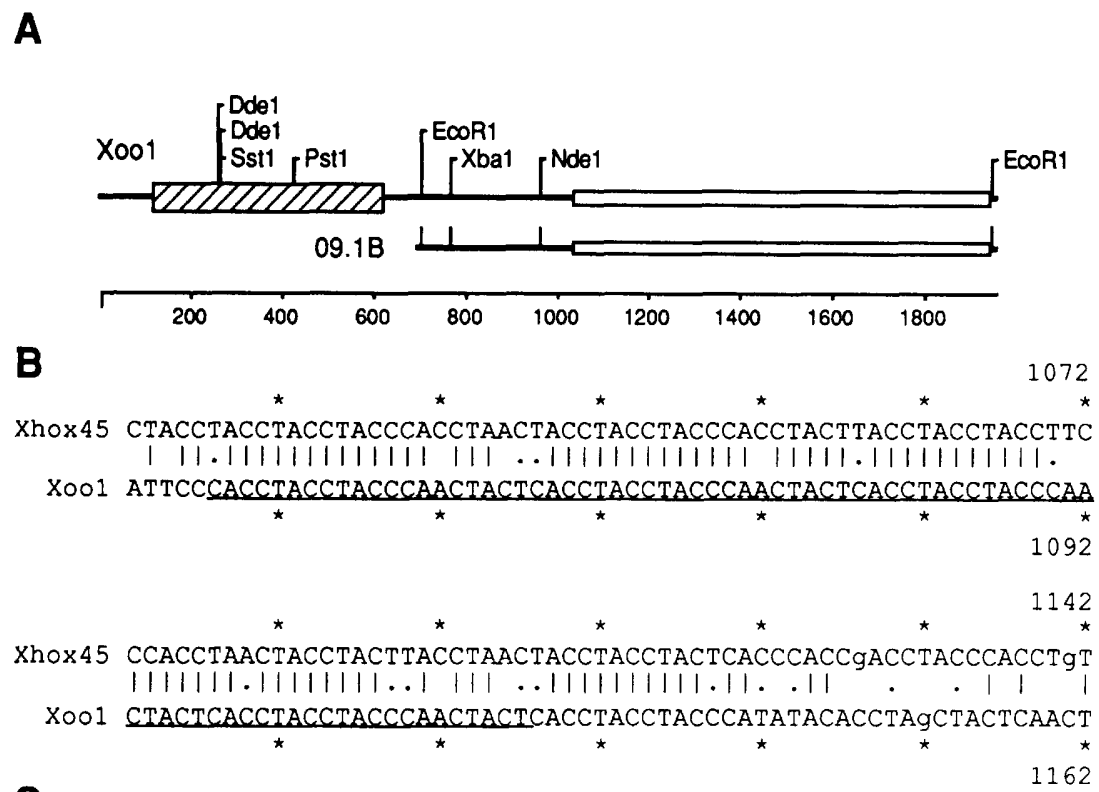

Position: $\quad \begin{array}{llllllllllllllllllll}0 & 1 & 2 & 3 & 4 & 5 & 6 & 7 & 8 & 9 & 10 & 11 & 12 & 13 & 14 & 15 & 16 & 17 & 18 & 19\end{array}$

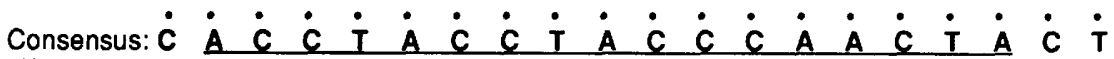
\%ldentity: $\quad \begin{array}{llllllllllllllllllllll} & 70 & 98 & 95 & 93 & 91 & 98 & 84 & 81 & 98 & 95 & 100 & 93 & 95 & 100 & 67 & 51 & 88 & 98 & 88 & 86\end{array}$ lines). Perfect matches are marked with vertical bars, and conservative (pyrimidine/pyrimidine) changes are marked by dots. The longest blocks of absolute sequence conservation between the two instability regions are 13 bases in length (underlined). Note the conservation of the A-every-fourth-base motif, even when additional A residues are present. As shown, the absolute conservation between the two sequences is $67.5 \%$ (81 of 120 bases) and can be increased to $81.7 \%(98 / 120)$ if conservative Py/Py substitutions are allowed. Note that the Xoo1 region begins with four perfect 20-base repeats (beginning at base 1038) Asterisks mark every tenth base, and guanosines are in lowercase. $(C)$ Weight matrix analysis of the potential endonuclease recognition sites found in $X I h b o x 2 B$ and $X 001$. The numerical position of each base is given at the top (Position). Twenty bases are shown because the minimal functional site, perhaps 17 bases in length, is found embedded within a slightly longer repeat unit (19 bases in XIhbox2B and 20 in Xoo1). Beneath each numbered position is given the base composition at that position within the repeats, read vertically $(G, A, T, C)$. The consensus sequence of the repeats, based on the most frequent base in each position, is also shown. The underlined portions of the consensus are the bases that are most highly conserved between XIhbox2B and Xoo1, and form a 17 base "core" element within the repeats. At the bottom, the percentage of the most frequently found base in each position is given (\% Identity).

RNA is also a potent competitor for the cleavage inhibitor in vitro (see Fig. 10, below). The complete Xoo1 sequence may be found in GenBank (accession number L20221). The putative translation product does not resemble any other protein in the data bases accessed by the BLAST program (Altschul et al. 1990) at the National Center for Biotechnology Information. Xoo1 mRNA is detectable by Northern blots only in very early-stage oocytes (B.D. Brown and I.D. Zipkin, unpubl.).

A polyadenylation signal is found upstream of the endonuclease recognition sequence at position 994 (underlined); however, the X001 cDNAs extend past this point. Although Xoo1 cDNAs were produced by oligo(dT) priming of poly $(\mathrm{A})^{+} \mathrm{RNA}$, transcripts polyadenylated at a site $3^{\prime}$ of the recognition region have not been detected. Figure 7 shows a Northern blot of both polyadenylated and nonadenylated RNA from Xenopus oocytes, probed with the 5' EcoRI fragment of Xoo1. A clear band of Xoo1 polyadenylated at position 994 is seen. Nonadenylated Xoo1 is present as well (Fig. 7) and appears as a smear between 2000 and 1000 bases long. This range is appropriate for Xoo1 RNA that is being cleaved throughout the length of the instability region (see below) and provides suggestive evidence that the endogenous Xoo1 mRNA is being cleaved in vivo.

\section{Identification of natural recognition sites by comparison of Xlhbox2B and Xool}

What sequence constitutes an endonuclease recognition site? We aligned the XIhbox $2 B$ destabilizing element and the first 120 bases of the Xoo1 element in a preliminary attempt to answer this question (Fig. 6B). Two perfectly conserved blocks, 13 bases in length (ACCTACCTACCCA, referred to as 13-mers), occur at the beginning of the target regions. These 13-mers are found, with minor sequence variations, throughout the $X_{001}$ instability region.

To define the recognition site more precisely and to develop better strategies for searching a data base, a weight matrix of 20-mers (based on the four perfect repeats in Xoo1) containing potential recognition sites from both Xlhbox2B and Xoo1 was constructed. The consensus and identity at each position are shown in 


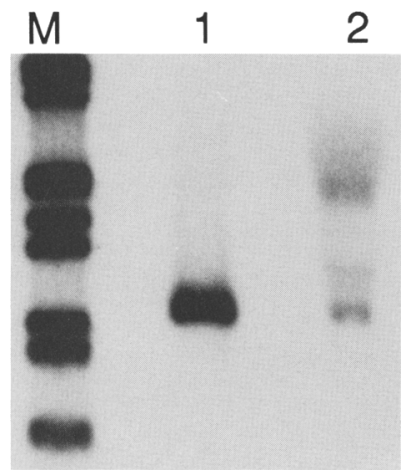

Figure 7. Northern blot showing Xoo1 mRNA populations in oocytes. Early oocyte total RNA was prepared and fractionated into polyadenylated and nonadenylated populations. Polyadenylated $(1 \mu \mathrm{g}$, lane 1$)$ and nonadenylated (38 $\mu \mathrm{g}$, lane 2) RNAs were run on denaturing agarose gels, blotted, and probed with the 5' EcoRI fragment of Xoo1 (which contains the Xoo1-coding region). The prominent band of Xoo1 polyadenylated upstream of the instability region is seen in lane 1 . Nonadenylated Xoo1 is also present and can be detected as a smear in lane 2. The interruption within the smear of nonadenylated Xoo1 is presumably attributable to ribosomal RNA.

Figure 6C. This assumes that most sites in Xoo1 are cleavable and, therefore, will provide information about the sequence specificity of the reaction. Where necessary, sites were allowed to overlap (XIhbox $2 B$ repeats are 19 bases long, in contrast to the 20-mers found in Xoo1). The comparison reveals several features, of which three are striking: First, a high level of similarity extends to 17 bases with the adenosine at position 17 being $98 \%$ conserved. This suggests that a recognition site may be at least 17 bases long (experimental evidence is given below). Second, the strong conservation of the CCC pyrimidine block in positions 10-12 that breaks up the ACCT repetition is one of the most well-conserved features of the repeats, suggesting a functional significance. Third, adenosine is found every 4 bases throughout the destabilizing element.

\section{Synthesis and cloning of functional cleavage sites}

We constructed oligomers of the 19-base repeat found in $X I h b o x 2 B$ to define a cleavage site and determine the effects of multiple sites on RNA half-lives. These synthetic sites were designed to allow ladders of multimers to be inserted into a Xenopus $\beta$-globin cDNA contained in the transcription vector pSP64 (Melton et al. 1984). Modified clones containing one to six sites were identified, and these templates were transcribed to produce ${ }^{32} \mathrm{P}$-labeled RNAs.

Figure 8A shows the vector and oligomer sequences. The insertion site, a filled-in BstEII site, is near the translation stop codon of the globin open reading frame (TAA, position 468 ). These modified $\beta$-globin clones containing synthetic sites are designated $\beta S S 2 . n$, where $n$ is the number of inserted sites. Figure $8 \mathrm{~B}$ shows a reaction time course (given in minutes above each lane) using an RNA containing five sites. The starting substrate is shown in lane $U(F=$ full length $)$. As the reaction progresses, the cleavage of the $\beta S S 2.5$ RNA almost reaches completion. The sizes of the cleavage fragments correspond to cuts within the inserted sequences, and this result confirms that RNA encoded by oligomer 5 is a functional endoribonuclease recognition site. In contrast, $X \beta \mathrm{m}$ RNA, which contains no recognition sites, and RNAs containing sites inserted in the antisense orientation are not cleaved at all (see below).

Because five distinct $3^{\prime}$ cleavage products are visible (lanes 16,32,64, marked by arrowheads), these data also suggest that each insert within $\beta$ SS2.5 functions independently. In this gel, the $3^{\prime}$ fragment ladder shows a clear progression produced by sequential cuts in the five recognition sites. A corresponding ladder is seen in gels resolving the $5^{\prime}$ cleavage fragments (not shown). The 19or 20-base spacing of sites found in Xlhbox2B and Xoo1 is also disrupted in this construct as a result of the insertion of DraI sites at the end of each artificial site; thus, the exact spacing of sites does not appear to be important.

\section{A single endonuclease recognition site is cleavable and additional sites lead to decreasing $m R N A$ half-lives}

To determine whether a single site could be cleaved, and whether multiple sites would be cleaved cooperatively, $\beta S S 2$ clones containing from one to six oligonucleotide insertions were transcribed and incubated under conditions of substrate excess in cleavage reactions (Fig. 8C). The time of incubation was adjusted to compensate for the rates of cleavage, from $12 \mathrm{~min}$ for $\beta$ SS2.1 (one site) to $2 \mathrm{~min}$ for $\beta$ SS2.6 (six sites), so that no more than $50 \%$ of the substrate was cleaved in any reaction.

The number of counts present as full-length RNA before and after the reaction were used to calculate the half-life of each RNA species. In this experiment, using a crude lysate, the half-life of unmodified $\beta$-globin RNA $(\mathrm{X} \beta \mathrm{m})$ was $57 \mathrm{~min}$. The insertion of a single endonuclease recognition ( $\beta S S 2.1$ ) site reduced the half-life of full-length material to $15 \mathrm{~min}$. The half-lives of each construct decreased linearly down to only $2.0 \mathrm{~min}$ for the $\beta S S 2.6$ RNA, with no evidence for cooperativity.

The presence of one recognition site insert dramatically changes the fate of an RNA in the oocyte lysate. Therefore, a single copy of the sequence ACCUACCUACCCACCUA is fully sufficient for recognition and cleavage by a sequence-specific endoribonuclease and, to our knowledge, is the first such complex RNase recognition site to be identified in a eukaryotic mRNA.

\section{The endoribonuclease and the protective factor} have different recognition site requirements

Synthetic sites in the $\beta S S 2$ RNAs are cleaved efficiently (Fig. 8B) and are bound by the protective factor (Fig. 1, lane $\beta S S 2 . n$; to assay for binding of protective factor, the 
Brown et al.

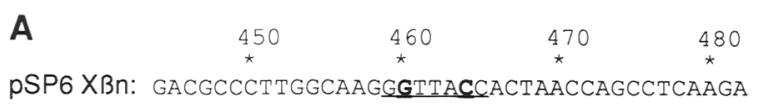

pSP6 XBn: GACGCCCTTGGCAAGGGTIACCACTAACCAGCCTCAAGA

Oligo 5: CTACCTACCTACCCACCTAITTAAA

Oligo 6: GTAgtTtAaAtAgGtgGgtaggtag

B
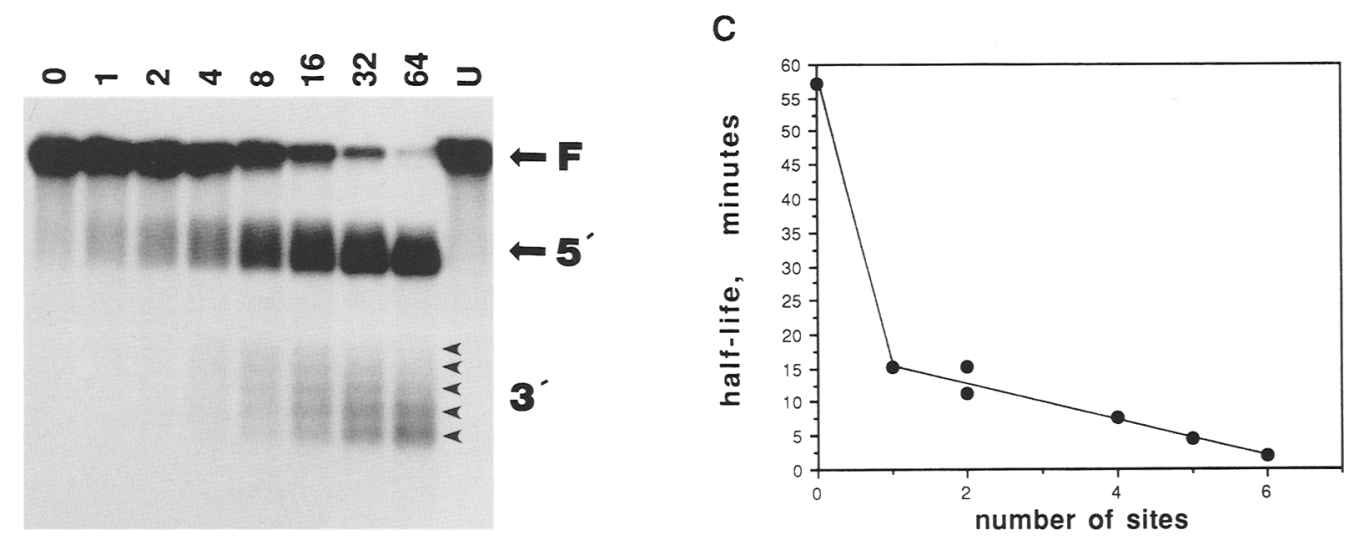

Figure 8. A Xenopus $\beta$-globin cDNA clone was used as a test vehicle for artificial recognition sites. $(A)$ Multiple copies of synthetic duplex DNA oligonucleotide recognition sites were inserted into pSP64 Xßm (Melton et al. 1984). The $\beta$-globin sequence is shown beginning at base 444. The insertion site was a filled in BstEII site (underlined GGTTACC) at position 459 . Oligonucleotide 5 (oligo 5 ; written $5^{\prime}$ to $3^{\prime}$ ) forms the sense strand of the duplex oligodeoxynucleotides and encodes an endoribonuclease recognition site that is found in XIhbox2B. The final six bases of oligo 5 contain a DraI restriction site (underlined) to allow identification of positive clones. Oligo 6 is the reverse complement of oligo 5. The effect of single and multiple inserts of the endoribonuclease recognition sites in the $\beta$-globin RNA were tested (see below). The context of each instability sequence insertion is given by $\mathbf{C}$ and $\mathbf{G}$ shown at the beginning and end of each insert within the $\beta$-globin sequence. $(B)$ Multiple cleavages occur in a $\beta$-globin mRNA containing multiple recognition sites. $\beta S S 2.5$ RNA (pSP64 X $\beta \mathrm{m}$ plus five sites) was incubated in a standard in vitro reaction for the times shown in minutes above each lane. $(F)$ The position of the full-length $\beta S S 2.5$ transcript (U was unincubated). As the reaction progresses, the amount of full-length transcript decreases, and 5' (arrow) and 3' (arrowheads) cleavage products are produced. In the 16, 32, and 64 min lanes, five distinct $3^{\prime}$ cleavage products are resolved; therefore, each site in $\beta S S 2.5$ is fully functional. $(C)$ Increasing the number of endonuclease recognition sites linearly decreases the half-life of synthetic $\beta$-globin RNAs. The half-life of each RNA was estimated by counting the full-length RNA band in each reaction. Note that the decrease in RNA half-life is linear. Direct detection of $3^{\prime}$ fragments confirm that $\beta S S 2.2$ and $\beta S S 2.3$ each contain two functional sites.

site is assayed as cold-competing RNA and its ability to stimulate cleavage of a standard radioactive substrate is assessed). To learn more about the sequence requirements of both the endonuclease and the protective factor, additional mutant sites were synthesized and cloned into the Xenopus $\beta$-globin cDNA. The sequences that have been tested for their ability to be cleaved by the endonuclease and/or bound by the protective factor are summarized in Figure 9.

Although the mutagenesis of the sequence has been far from saturating, several important conclusions can be drawn from this summary: First, the sequence ACCUACCUACCCACCUA (the 17-mer) is sufficient for either cleavage or binding the protective factor. Second, the sequences required for recognition by both factors are flexible. The pattern "A (adenosine) every fourth base" does not need to be maintained for longer than 17 bases in a row. For example, the DraI sites between sites 1 and 2 in $\beta S S 2$ alter the regions normally conserved between natural recognition sites, creating polypurine tracts (AAA and AAAA, respectively).

We may also conclude from the data in Figure 9 that the Xenopus endonuclease and protective factor have slightly different recognition site requirements: The changes made in the $3^{\prime}$ half of the site do not affect recognition by the protective factor, but they do affect the endonuclease activity (cf. sites 1 and 2 with sites 4 and 7). The position and presence of one or more of the ubiquitous uridines within the pyrimidine blocks appears to be a requirement for protective factor recognition (cf. sites 1 and 2-3 with sites 4-5), whereas the endonuclease is tolerant of the change in position (cf. Xlhbox2B, Xoo1, and site 3). The data suggest that the protective factor binding site is a subset of the endonuclease recognition site.

\section{Drosophila embryos contain both an endoribonuclease} activity and protective factor

In an attempt to determine whether or not the endonuclease activity is widely conserved within the animal kingdom, we tested a lysate made from Drosophila melanogaster embryos for its ability to recognize and cleave the Xenopus recognition sequences. Figure 10 shows a competition assay comparing a Xenopus oocyte lysate with a Drosophila embryo lysate /a gift of L. von Kalm 


\begin{tabular}{|c|c|c|c|}
\hline Site & Sequence & & $\mathrm{N}$ \\
\hline XIhbox2B & 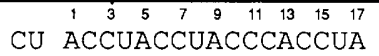 & CUACCU & + \\
\hline Xoo1 & UC ACCUACCUACCCAAAUA & CUCACC & + \\
\hline 1 & CU ACCUACCUACCCACCUA & UUUAAA & + \\
\hline 2 & AA ACCUACCUACCCAUUUA & AAACCU & + \\
\hline 3 & CU ACUCACUCACCCACUCA & UUUAAA & + \\
\hline 4 & CC ACCUACCUAUUUAGGAU & CCACCU & - \\
\hline 5 & 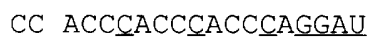 & CCACCC & - \\
\hline 6 & $\mathrm{CU}$ GCCUGCCUGCCCGCCUG & UUUAAA & - \\
\hline 7 & UU ACCUACCUACCCACGUU & ACCACU & - \\
\hline
\end{tabular}

Figure 9. A comparison of potential recognition sites for the endoribonuclease activity and the protective factor reveals different requirements for recognition. Nine potential endonuclease recognition sites (Site) are listed: Xlhbox2B and Xoo1 are consensus sequences derived from naturally occurring, slightly variable repeats (see text and other figures). The numbers 1-7 are artificial sequences constructed using DNA oligonucleotides (see text and methods). Underlined bases indicate differences from, or alterations in, the Xhox 45 recognition sequence. The column labeled $\mathrm{N}$ indicates the ability of a given sequence to function as a substrate for the endonuclease; $\mathrm{P}$ indicates the ability to function as a competitor for the protective factor. Assay results were quantitated by cutting radiolabeled substrate RNA out of dried gels and Cerenkov counting as given in Materials and methods and are represented qualitatively above. Functional sites are marked plus $|+|$, and those that are nonfunctional or inefficiently recognized are labeled minus $(-)$. The bases within each site are numbered 1-17, beginning with the first conserved adenosine. Two additional bases $5^{\prime}$ and five bases $3^{\prime}$ of the recognition sites are given to establish the context of each site.

and B. Zhou, University of California, Berkeley). The ramps above lanes 2-4 and 5-7 indicate increasing amounts (from 0-0.5 $\mu \mathrm{g}$ ) of cold competitor RNA added to the reactions. Lane 1 shows the unincubated substrate RNA, ${ }^{32} \mathrm{P}$-labeled $\beta S S 2.1$, which contains a single recognition site. In lane 2 the substrate RNA is cut poorly even in Xenopus oocyte lysate under the reaction conditions (a low concentration of recognition sites). As 0.1 and $0.5 \mu \mathrm{g}$ of competitor RNA are added to the reaction (lanes 3 and 4, respectively), the cleavage efficiency increases. The positions of the Xenopus endonuclease cleavage products are indicated by arrowheads.

Figure 10, lanes 5-7, shows a series of reactions identical to those in lanes $2-4$, respectively, except that a Drosophila embryo lysate is used. The Drosophila lysate contains an uncharacterized nuclease activity that produces a slightly shortened substrate RNA band /small arrowhead, lanes 5 and 6, most likely attributable to an exonuclease activity). As more RNA is added to the reaction, this band is not produced (lane 7). When the BSS2.1 substrate RNA alone is added to the Drosophila lysate (lane 5), no specific endonucleolytic cleavage product is detectable (as in lane 2). As more endonuclease recognition sites are added to the reaction in the form of 09.1B competitor RNA, cleavage products matching those formed in the Xenopus lysate are produced (lanes 6,$7 ; 5^{\prime}$ and $3^{\prime}$ arrowheads). This result demonstrates that
Drosophila embryos contain an endonucleolytic activity capable of recognizing the same sites as the Xenopus endonuclease. Furthermore, the increase of cleavage upon the addition of specific competitor RNA shows that Drosophila embryos also contain a protective factor that recognizes these sites.

Given this remarkable functional conservation of activities, one must ask whether Drosophila strains also have RNAs that contain the recognition sequences. Low stringency Southern blots of Drosophila genomic DNA using Xenopus recognition sequence DNA as a probe reveal several distinct bands (data not shown). However, in screens of Drosophila cDNA libraries, we have yet to find sequences that are recognized by the endonuclease.

\section{Discussion}

We have presented data that demonstrate a new example of targeted mRNA degradation in Xenopus. A sequencespecific endoribonuclease is functional in the absence of translation and needs only a simple buffer. Although

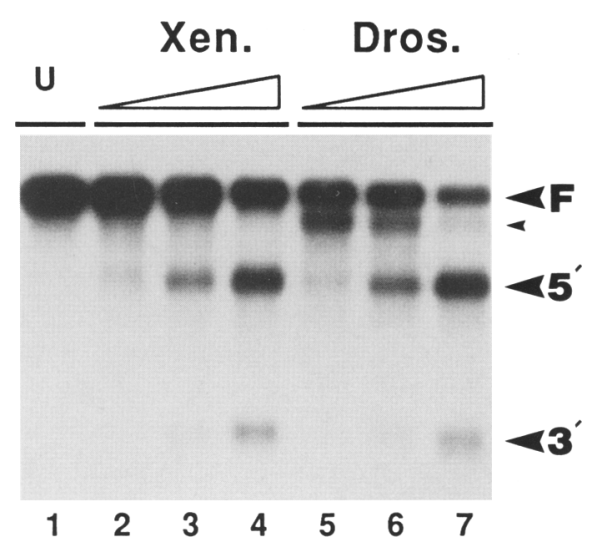

Figure 10. Drosophila embryos contain an endoribonuclease activity and a protective factor that also recognizes the Xenopus instability sites. One hundred nanograms of unincubated ${ }^{32} \mathrm{P}$ labeled $\beta S S 2.1$ RNA (containing only a single recognition site) is shown in lane 1 . Lane 2 shows the substrate RNA incubated in crude Xenopus (Xen.) lysate alone, and under these conditions very little cleavage is detectable. Lanes 3 and 4 also contained 0.1 and $0.5 \mu \mathrm{g}$, respectively, of cold 09.1B competitor RNA. When competitor RNA is added, the full-length RNA $(F)$ is once again efficiently cleaved in a crude Xenopus oocyte lysate into $5^{\prime}$ and $3^{\prime}$ cleavage products (lane 4 ). A partially fractionated, 0 to 12-hr Drosophila embryo lysate preparation (see Materials and methods) was used in the assays shown in lanes 5-7 (Dros.), also containing $0,0.1$, and $0.5 \mu \mathrm{g}$ of $09.1 \mathrm{~B}$ competitor RNA, respectively. Lane 5 shows very little cleavage of $\beta S S 2.1$ at the recognition site, but a slightly shortened nonspecific product is detected (small arrowhead). Lanes 6 and 7 show two important results: First, the $\beta S S 2.1$ is cleaved into the same $5^{\prime}$ and $3^{\prime}$ fragments as those seen in lane 4; and second, the efficiency of the cleavage increases as specific competitor RNA is added to the reaction, revealing the presence of the protective factor as well. The oocyte lysate reactions contained $72 \mu \mathrm{g} / \sim 2 \mathrm{mg} / \mathrm{ml}$ final), and the embryo lysate reactions contained $42 \mu \mathrm{g} \mid \sim 1$ $\mathrm{mg} / \mathrm{ml}$ final) of protein. 
cleavage in the fractionated extract yields RNA fragments that are moderately stable, the consequences of cleavage of mRNA in the cell are the loss of the poly(A) tail from the $5^{\prime}$ fragment and the loss of the cap from the $3^{\prime}$ fragment. These events will lead to rapid decreases in both the translatability and stability of target mRNAs in vivo. Injections of the RNA into oocytes have confirmed the presence of the endoribonuclease in both cytoplasmic and nuclear compartments (data not shown), but the subcelluar distribution of the protective activity has not been determined. We propose the name "Xixernase" for the endoribonuclease [for RNase that cuts XlHbox2B, human int-2 (B.D. Brown, I.D. Zipkin, and R.M. Harland, in prep.), and Xoo1].

We have attempted to test whether the cleavage might be catalyzed by the RNA recognition sequence (a selfcleavage reaction). Incubation under various standard self-cleaving conditions, and with a variety of lengths of substrates, has never given any indication of cleavage. The combination of the very short length of a single functional recognition site and the lack of guanosine residues would preclude any predictable base-paired secondary structure within a recognition site; this also argues against the possibility of a self-cleaving mechanism for the reaction .

The extracts also contain a factor that protects RNA from the endonuclease. The protective factor can be titrated with excess recognition sites, leading to an increase in cleavage. The result that the inhibitor can be titrated only with specific RNAs suggests that the inhibitor does not function by binding to the endoribonuclease (as RNasin binds RNase) or to nonspecific RNA but, rather, that the inhibitor binds directly to the endonuclease recognition sequences. The endonuclease inhibitor is therefore also a sequence-specific RNA-binding activity. The observation of saturation by a cleavable RNA species argues against the possibility that the mechanism of cleavage is based on an intermolecular RNA/RNA interaction analogous to the self-cleaving RNA reactions that are known.

Furthermore, the difference in sequence tolerated by the protective factor versus the nuclease argues against the possibility that the protective factor is a defective nuclease. The protective factor can be purified away from the nuclease, suggesting that it could be biochemically purified and analyzed in detail. From the number of moles of sites that can be added to the reaction to stimulate cleavage, we can estimate the molar amount of protective factor and conclude that it must be abundant in oocytes /corresponding to a tenth to a hundredth of the number of ribosomes in the oocyte). In contrast, the nuclease may have a high specific activity and be quite rare.

So far, we have identified two genes, $X 1 h b o x 2 B$ and Xoo1, which produce RNAs containing recognition sites. Screening libraries with the recognition sites identified only these, and both have multiple sites. We probably would not detect cDNAs that contain single sites or active sites that are different from the canonical site. The exact sequences required for both the endonuclease and protective activities are flexible, and the activities have distinct, but overlapping, sequence requirements. We have not yet saturated the sites with mutations and therefore cannot predict the range of sites that might be substrates for the nuclease.

We have also presented evidence that both the endonuclease and protective factor are found in Drosophila embryos, as shown by direct cleavage of RNAs containing synthetic recognition sites. Similar results have been obtained with sea urchin embryo extracts but not with yeast or Escherichia coli, raising the possibility that this degradation system is used throughout the animal kingdom.

\section{Comparison of Xlhbox2B/Xool and A+U-rich RNA degradation}

Extensive work on eukaryotic RNA destabilization has been done on mRNAs with A+U-rich $3^{\prime}$ UTR regions and has led to the identification of three different types of stability determinants: AUUUA elements, poly(U) or U-rich tracts within the A+U-rich regions (Shyu et al. 1991; You et al. 1992), and other destabilizing regions contained within the open reading frames (Shyu et al. 1989; Wisdom and Lee 1991; Bernstein et al. 1992). Although the search for the nucleases that regulate RNA turnover has been difficult, the search for other activities that bind to $\mathrm{A}+\mathrm{U}$-rich regions has been fruitful. Two groups (Vakalopoulou et al. 1991; Myer et al. 1992) have reported that a $32-\mathrm{kD}$ protein can interact with AUUUA repeats. However, no direct nuclease activity was associated with this $32-\mathrm{kD}$ protein. You et al. (1992) have identified four different proteins that interact specifically with $\mathrm{U}$-rich elements within the $\mathrm{A}+\mathrm{U}$ regions of the c-fos 3' UTR. In particular, the level of a 37-kD protein is increased when cells are serum stimulated and c-fos RNA is destabilized and decreased when cells are treated with drugs known to stabilize c-fos RNA. This correlation suggests that the $37-\mathrm{kD}$ protein in particular may be involved in the removal of poly(A) from c-fos, but once again, no nuclease activity was detected in any of the nucleoprotein complexes.

Savant-Bhonsale and Cleveland (1992) have recently clarified the translational requirement for degradation of $\mathrm{A}+\mathrm{U}$-rich mRNAs and described a new aspect of the degradative machinery: A large complex is formed on the granulate-macrophage colony-stimulating factor (GMCSF) A+U-rich region in vivo. The assembly of this complex requires the presence of AUUUA motifs and active translation of the target mRNA, although the AUUUA itself must be outside the open reading frame.

The cleavage of Xlhbox2B/Xoo1 RNA in Xenopus oocytes differs from $A+U$-rich RNA degradation in human cell lines in two significant ways: First, Xlhbox2B/ Xoo1 cleavage does not require translation or the presence of polysomes, unlike most $\mathrm{A}+\mathrm{U}$ degradation systems known to date (including in vitro systems; Bernstein et al. 1992); and second, endonucleolytic cleavage of $X l h b o x 2 B$ is the first detectable step, as opposed to the initial poly(A) shortening event seen with 
mRNAs that contain A+U-rich elements (Brewer and Ross 1988; Wilson and Treisman 1988; Shyu et al. 1989,1991; Laird-Offringa et al. 1990).

Bernstein et al. (1992) have further investigated the 182-nucleotide region of the c-myc open reading frame that is capable of conferring instability on exogenous RNAs and have produced an in vitro degradation reaction. Using competition assays, these investigators find that the destabilizing sequence is bound by a $75-\mathrm{kD}$ protein that acts as a protective factor in a manner similar to the protective factor that we have described in Xenopus. However, unlike the in vitro reaction that we describe, polysomes are required for the degradation of RNAs containing the c-myc stability determinant region.

\section{Sequence specificity of the endoribonuclease and protective factors}

What sequence constitutes a functional endonuclease recognition site? A comparison of naturally occurring sequences, Xlhbox2B and Xoo1, that are efficiently cleaved in vitro provides suggestive evidence. The natural 20-mer consensus is 5'-CACCUACCUACCCAA ${ }^{\mathrm{C}}$ / ${ }_{A}$ UACU- $3^{\prime}$. The ACCU repeat is thus broken up by two features: (1) the highly conserved CCC block, and (2) the flexibility of the A/C position, which strengthens the argument that the site is not a tetramer or pentamer ACCU. Here, the choice of the $C$ that marks the 5' end is set by the starting point of the repetitive regions themselves (Fig. 6B).

A more thorough examination of the sequences that may define a recognition site is shown in Figure 9. Although the mutants that have been constructed do not approach an exhaustive set, important conclusions can be drawn about what constitutes a recognition site. First, the sequence is somewhat degenerate. Second, the entire 19- to 20-mer repeat found in Xlhbox2B and Xoo1 is not required either for cleavage or binding of the protective factor. Site 2 has no sequence similarity to the naturally conserved bases between 17-mers (AAAA), and the identity $(A, U$, or $C)$ of the bases preceding the first and last base of a site (Fig. 9) apparently have no effect on site cleavage (guanosine remains untested). Third, the position of the uridines in the site has a greater effect on the protective factor activity than on the endonuclease activity. We are then left with the following description of a sequence sufficient for endonuclease recognition: adenosine every fourth base for up to 17 bases, separated by blocks of pyrimidines, including one or more uridines. This information may be valuable for identifying candidate recognition sequences in nucleic acid data bases.

\section{Conservation of this regulatory system}

Perhaps the most surprising of the results that we have presented is the functional conservation of these activities and sequences over vast evolutionary distances. $\mathrm{Xe}$ nopus and Drosophila appear to have interchangeable sequence-specific endonuclease and protective acitivites. We may reasonably assume that Drosophila strains also produce RNAs recognized by these activities and that this system of RNA turnover is found in most, or all, animals. The possibility of changing the levels of nuclease, protective factor, and cis-acting recognition sites provides rich possibilities for in vivo regulation of RNA turnover by endonucleolytic cuts.

Experimentally, it has been difficult to determine the physiological role of the nuclease and protective factors in Xenopus, or even to prove that endogenous RNAs are substrates in vivo. Further purification and cloning of Xixernase and the protective activity should allow the functional study of these activities in a genetically more tractable organism.

\section{Materials and methods}

Isolation of oocytes and embryos

Oocytes for large-scale lysate preparation were prepared as follows: Ovaries were isolated and washed in modified Barth's saline (MBS) until cleared of blood and fat and then treated with $1 \mathrm{mg} / \mathrm{ml}$ of collagenase in MBS, gentamycin $(50 \mathrm{mg} / \mathrm{ml})$, and tetracycline $(8 \mathrm{mg} / \mathrm{ml})$ on a rotating platform. After up to $4 \mathrm{hr}$ the oocytes were washed thoroughly in MBS by mixing and settling in graduated cylinders with careful attention to removing the remaining fat body fragments and connective tissues. In some experiments the small oocytes were collected by repeatedly siphoning off the top layer. For stage-specific lysates the oocytes were then hand sorted into pools of stages I and II or stages V and VI (Dumont 1972). Eggs and embryos were prepared on a small scale by standard procedures. RNA and Northern blots were prepared by standard procedures.

\section{Oocyte, egg, and embryo lysates}

Settled and washed oocytes or embryos were washed twice more in ice-cold MBS and then twice in ice-cold TKb $[90 \mathrm{mM}$ $\mathrm{KCl}, 30 \mathrm{mM}$ Tris- $\mathrm{HCl}$, and $10 \mathrm{mM} \mathrm{Na}_{2} \beta$-glycerophosphate $/ \mathrm{pH}$ 8.0 ) at $24^{\circ} \mathrm{Cl}$, followed by two final washes in ice-cold lysis buffer [TKb plus $1 \mathrm{~mm}$ each dithiothreitol (DTT) and phenylmethylsulfonyl fluoride (PMSF)]. Lysates were produced by two different methods: (1) Whole, large oocytes were crushed by ultracentrifugation in lysate buffer; and (2) all stages of oocytes were homogenized together in lysate buffer in a Dounce homogenizer and then ultracentrifuged (modified from Ng et al. 1979; Glikin et al. 1984; Almouzni and Méchali 1988). Centrifugation was at $100,000 \mathrm{~g}$ for $2 \mathrm{hr}$ at $2^{\circ} \mathrm{C}$. All of the recovered lysate was mixed before freezing aliquots in liquid nitrogen. Thawed crude lysate was microcentrifuged for $15 \mathrm{~min}$ at $4^{\circ} \mathrm{C}$ before assaying or determining the protein concentrations. Protein concentrations from various crude lysate preparations ranged from 4 to $20 \mathrm{mg}$ / $\mathrm{ml}$.

\section{Lysate fractionation}

Basic protein methods were as given in Scopes (1982), Harris and Angal (1989), or as recommended by reagent suppliers. Partially purified endonuclease activity was prepared using a $55-70 \%$ ammonium sulfate precipitation, resuspension into $1 \mathrm{M}$ ammonium sulfate $\mathrm{HIC}$ [hydrophobic interaction chromatography buffer: $1 \mathrm{M}(\mathrm{NH})_{2} \mathrm{SO}_{4}, 30 \mathrm{mM} \mathrm{K}{ }_{2} \mathrm{HPO}_{4}, 1 \mathrm{mM} \mathrm{MgCl}_{2}(\mathrm{pH} 6.8)$ at $24^{\circ} \mathrm{C}$ ] and passage over a phenyl-Sepharose column. The protein was eluted with a $550-100 \mathrm{mM}(\mathrm{NH})_{2} \mathrm{SO}_{4}$ step in HIC buffer plus $15 \%$ ethylene glycol and then dialyzed into dye column buffer (DCB: $100 \mathrm{~mm} \mathrm{KCl}, 30 \mathrm{~mm} \mathrm{~K}_{2} \mathrm{HPO}_{4} 3 \mathrm{H}_{2} \mathrm{O}, 1 \mathrm{mM} \mathrm{MgCl} \mathrm{Mg}_{2}$ 
$10 \%$ glycerol, and $0.1 \%$ Tween 20 ) and successively loaded onto and eluted from Blue- and Red-Sepharose columns using gradients of $\mathrm{KCl}$ in DCB (from $220-330 \mathrm{mM} \mathrm{KCl}$ for Blue-Sepharose and $800-1000 \mathrm{~mm} \mathrm{KCl}$ for Red-Sepharose). The endonuclease activity was purified almost 10,000 -fold at this point in the preparation, and most of the protective factor had been removed. Drosophila embryonic lysate was prepared from 0- to 12-hr Drosophila embryos as described in Soeller et al. (1988) and fractionated using a $0.1-0.5 \mathrm{M} \mathrm{KCl}$ wash from a heparin sulfate column.

\section{Endonuclease reaction conditions}

The unit definition of the endoribonuclease activity is 10 pmoles of the recognition site $\beta S S 2$ cleaved in $30 \mathrm{~min}$ at $24^{\circ} \mathrm{C}$. One hundred nanograms of $\beta$ SS 2.4 RNA contains 1.3 pmole of recognition sites, and $100 \mathrm{ng}$ of the $09.1 \mathrm{~B}$ transcript contains $\sim 9.1$ pmoles of sites. Typical reactions contained $100 \mathrm{ng}$ each of $\beta S S 2.4$ and 09.1B RNAs in a final volume of $65 \mu \mathrm{l}$. Competition assays contained from 0 to $8 \mu \mathrm{g}$ of $09.1 \mathrm{~B}$ RNA. Reaction buffer consisted of $25-80 \mathrm{mM} \mathrm{KCl}, 30 \mathrm{~mm}$ bis-trispropane, $2 \mathrm{~mm}$ $\mathrm{MgCl}_{2}, \pm 10 \%$ glycerol at a final pH of $8.4-8.5$ at $24^{\circ} \mathrm{C}$. Protein concentrations in crude lysate reactions were from 0.3 to 1.0 $\mathrm{mg} / \mathrm{ml}$ for Xenopus oocyte lysate and $1.3 \mathrm{mg} / \mathrm{ml}$ for Drosophila embryonic lysate. All reactions were stopped by the addition of $0.1 \%$ SDS in $100 \mathrm{~mm} \mathrm{NaCl}, 300 \mathrm{~mm} \mathrm{NaOAc}$, and $10 \mathrm{~mm}$ EDTA after the incubation times given in each experiment. Reactions using crude lysate were treated with proteinase $\mathrm{K}$ in the stop buffer at $37^{\circ} \mathrm{C}$ for $30 \mathrm{~min}$ and then phenol and phenol-chloroform extracted. The samples were precipitated and resuspended in formaldehyde sample buffer (Sambrook et al. 1989). RNAs in reactions using partially purified activity were precipitated with two volumes of ethanol immediately after the addition of the stop buffer and resuspended in the sample buffer described above. RNA samples were run on formaldehyde-agarose gels.

\section{Artificial recognition site construction and in vitro transcriptions}

The Xlhbox $2 B$ and Xhox 36 cDNAs, their derivatives, and the in vitro transcription reaction conditions have been described previously (Brown and Harland 1990). Artificial cleavage substrates were made by inserting ladders of duplex oligodeoxynucleotides into a Xenopus $\beta$-globin cDNA (pSP64 X $3 \mathrm{~m}$ ) according to standard methods (Sambrook et al. 1989). Positive clones were identified by restriction mapping on polyacrylamide gels, and the sequences of all clones used in this work were confirmed by dideoxy sequencing.

\section{Library screens}

A ${ }^{32}$ P-labeled probe consisting of the nuclease recognition region identified in Xlhbox2B (Brown and Harland 1990) was synthesized in a standard PCR reaction and used to probe a Xenopus ovary (obtained from Doug Melton, Harvard) and neurulastage embryo cDNA libraries at low stringency. Approximately 400,000 plaques total were screened. Two clones from the oocyte library, named $09.1(\sim 1750$ bases $)$ and $09.2(\sim 1100$ bases|, were from a previously uncharacterized gene, now named Xoo1.

\section{Acknowledgments}

We thank Alan Sachs and Mike Sheets for critical comments on the manuscript, Doug Melton for the ovary library, Paul Krieg for the pSP6X $\beta \mathrm{m}$ clone, and Laurie van Kalm and Bing Zhou for
Drosophila extracts. This work was supported by the National Institutes of Health.

The publication costs of this article were defrayed in part by payment of page charges. This article must therefore be hereby marked "advertisement" in accordance with 18 USC section 1734 solely to indicate this fact.

\section{References}

Aghib, D.F., J.M. Bishop, S. Ottolenghi, A. Guerrasio, A. Serra, and G. Saglio. 1990. A 3' truncation of MYC caused by chromosomal translocation in a human $\mathrm{T}$-cell leukemia increases mRNA stability. Oncogene 5: 707-711.

Almouzni, G. and M. Méchali. 1988. Assembly of spaced chromatin promoted by DNA synthesis in extracts from Xenopus eggs. EMBO I. 7: 665-672.

Altschul, S.F., W. Gish, W. Miller, E.W. Myers, and D.J. Lipman. 1990. Basic local alignment search tool. I. Mol. Biol. 215: 403-410.

Atwater, J.A., R. Wisdom, and I.M. Verma. 1990. Regulated mRNA stability. Annu. Rev. Genet. 24: 519-541.

Bandyopadhyay, R., M. Coutts, A. Krowczynska, and G. Brawerman. 1990. Nuclease activity associated with mammalian mRNA in its native state: Possible basis for selectivity in mRNA decay. Mol. Cell. Biol. 10: 2060-2069.

Bernstein, P.L., D.J. Herrick, R.D. Prokipcak, and J. Ross. 1992. Control of $c-m y c$ mRNA half-life in vitro by a protein capable of binding to a coding region stability determinant. Genes \& Dev. 6: 642-654.

Brewer, G. 1991. An A + U = rich element RNA-binding factor regulates c-myc stability in vitro. Mol. Cell. Biol. 11:24602466.

Brewer, G. and J. Ross. 1988. Poly(A) shortening and degradation of the $3^{\prime} \mathrm{A}+\mathrm{U}$-rich sequences of human c-myc mRNA in a cell-free system. Mol. Cell. Biol. 8: 1697-1708.

Brown, B.D. and R.M. Harland. 1990. Endonucleolytic cleavage of a maternal homeo box mRNA in Xenopus oocytes. Genes \& Dev. 4: 1925-1935.

Dumont, J.N. 1972. Oogenesis in Xenopus laevis (Daudin) 1. Stages of oocytes development in laboratory maintained animals. J. Morphol. 136: 153-180.

Fritz, A.F., K.W.Y. Cho, C.V.E. Wright, B.G. Jegalian, and E.M. DeRobertis. 1989. Duplicated homeo box-containing genes in Xenopus. Dev. Biol. 131: 584-588.

Glikin, G.C., I. Ruberti, and A. Worcel. 1984. Chromatin assembly in Xenopus oocytes: In vitro studies. Cell 37: 33-41.

Hallböök, F., C.F. Ibáñez and H. Persson. 1991. Evolutionary studies of the nerve growth factor family reveal a novel member abundantly expressed in Xenopus ovary. Neuron 6: $845-858$.

Harris, E.L.V. and S. Angal, 1989. Protein purification methods. Oxford University Press, New York.

Laird-Offringa, I.A., C.L. DeWit, P. Elfferich, and A.J. Van der Eb. 1990. Poly(A) tail shortening is the translation-dependent step in c-myc mRNA degradation. Mol. Cell. Biol. 10: 6132-6140.

Lee, W.M., C. Lin, and T. Curran. 1988. Activation of the transforming potential of the human fos proto-oncogene requires message stabilization and results in increased amounts of partially modified fos protein. Mol. Cell. Biol. 8: 5521-5527.

Melton, D.A., P.A. Krieg, M.R. Rebagliati, T. Maniatis, K. Zinn, and M.R. Green. 1984. Efficient in vitro synthesis of biologically active RNA and RNA hybridization probes from plasmids containing a bacteriophage SP6 promoter. Nucleic Acids Res. 12: 7035-7056. 
Müller, M.M., A.E. Carrasco, and E.M. DeRobertis. 1984. A homeo-box containing gene expressed during oogenesis in $\mathrm{Xe}$ nopus. Cell 39: 157-162.

Myer, V.E., S. Lee, and J. Steitz. 1992. Viral small nuclear ribonucleoproteins bind a protein implicated in messenger RNA destabilization. Proc. Natl. Acad. Sci. 89: 1296-1300.

Ng, S.Y., C.S. Parker, and R.G. Roeder. 1979. Transcription of cloned Xenopus 5S RNA genes by $X$. laevis RNA polymerase III in reconstituted systems. Proc. Natl. Acad. Sci. 76: 136140.

Sambrook, J., E.F. Fritsch, and T. Maniatis. 1989. Molecular cloning: A laboratory manual, 2nd ed. Cold Spring Harbor Laboratory Press, Cold Spring Harbor, New York.

Savant-Bohnsale, S. and D.W. Cleveland. 1992. Evidence for instability of mRNAs containing AUUUA motifs mediated through translation-dependent assembly of a $>20$ S degradation complex. Genes \& Dev. 6: 1927-1939.

Scopes, R. 1982. Protein purification. Springer-Verlag. New York.

Scott, M.P. 1992. Vertebrate homeobox gene nomenclature. Cell 71: 551-553.

Shyu, A.-B., M.E. Greenberg, and J.G. Belasco. 1989. The c-fos transcript is targeted for rapid decay by two distinct mRNA degradation pathways. Genes \& Dev. 3: 60-72.

Shyu, A.-B., J.G. Belasco, and M.E. Greenberg. 1991. Two distinct destabilizing elements in the c-fos message trigger deadenylation as a first step in rapid mRNA decay. Genes \& Dev. 5: 221-231.

Soeller, W.C., S.J. Poole, and T. Kornberg. 1988. In vitro transcription of the Drosophila engrailed gene. Genes \& Dev. 2: $68-81$.

Stoeckle, M.Y. and H. Hanafusa. 1989. Processing of 9E3 mRNA and regulation of its stability in normal and Rous sarcoma virus-transformed cells. Mol. Cell. Biol. 9: 4738-4745.

Vakalopoulou, E., J. Schaack, and T. Shenk. 1991. A 32-kilodalton protein binds to AU-rich domains in the 3' untransalted regions of rapidly degraded mRNAs. Mol. Cell. Biol. 11: 3355-3364.

Wilson T. and R. Treisman. 1988. Removal of poly(A) and consequent degradation of c-fos mRNA facilitated by $3^{\prime}$ AU-rich sequences. Nature 336: 396-399.

Wisdom, R. and W. Lee. 1991. The protein-coding region of c-myc mRNA contains a sequence that specifies rapid mRNA turnover and induction by protein synthesis inhibitors. Genes \& Dev. 5: 232-243.

Wright, C.V.E., K.W.Y. Cho, A. Fritz, T.R. Bürglin, and E.M. DeRobertis. 1987. A Xenopus laevis gene encodes both homeo box-containing and homeo box-less transcripts. EMBO I. 6: 4083-4090.

Xing, Y.Y. and A. Worcel. 1989. A 3' exonuclease activity degrades the pseudogene 5S RNA transcript and processes the major oocyte 5S RNA transcript in Xenopus oocytes. Genes \& Dev. 3: 1008-1018.

You, Y., C.-Y.A. Chen, and A.-B. Shyu. 1992. U-rich sequence binding proteins interacting with a 20 -nucleotide U-rich sequence in the $3^{\prime}$ untranslated region of c-fos mRNA may be involved in the first step of c-fos mRNA degradation. Mol. Cell. Biol. 12: 2931-2940. 


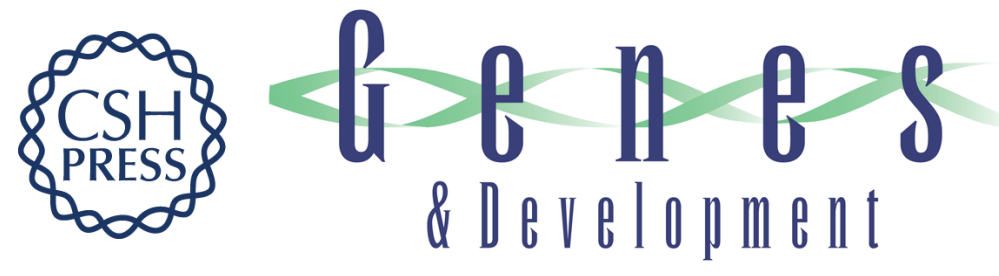

\section{Sequence-specific endonucleolytic cleavage and protection of mRNA in Xenopus and Drosophila.}

B D Brown, I D Zipkin and R M Harland

Genes Dev. 1993, 7:

Access the most recent version at doi:10.1101/gad.7.8.1620

References This article cites 31 articles, 18 of which can be accessed free at: http://genesdev.cshlp.org/content/7/8/1620.full.html\#ref-list-1

License

Email Alerting Service right corner of the article or click here.

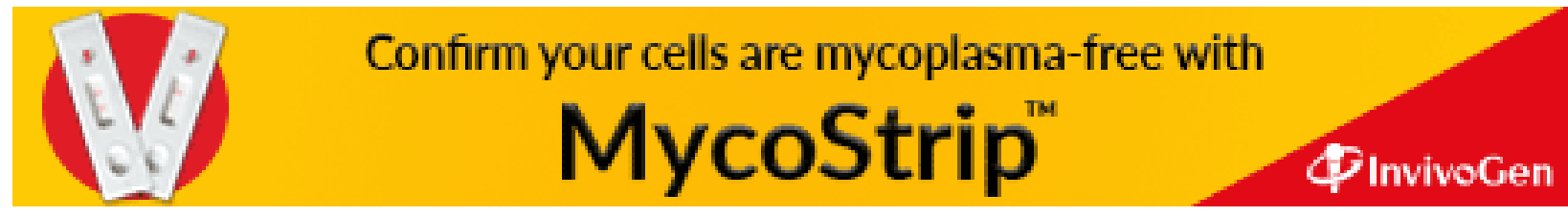

